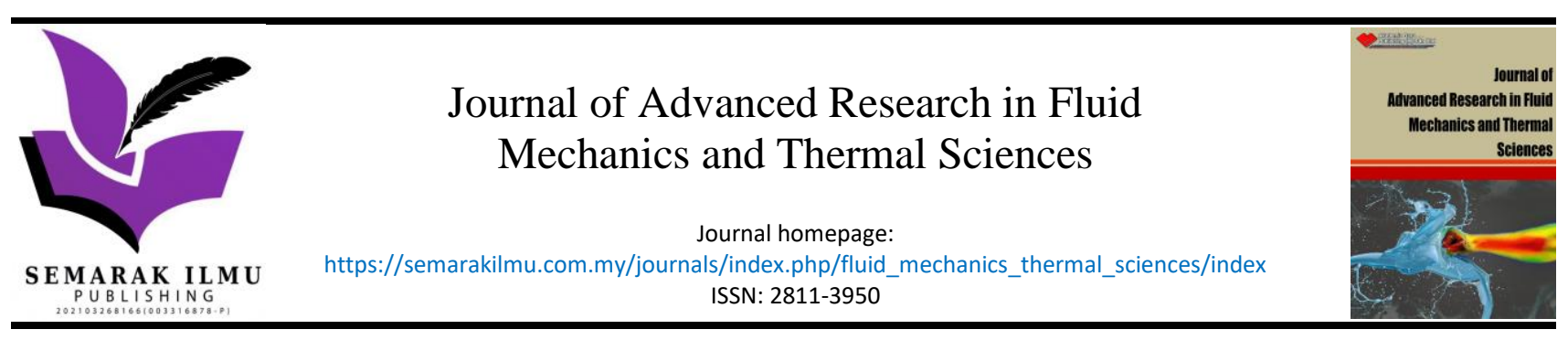

\title{
Optimisation of H-Darrieus VAWT Solidity for Energy Extraction in Cooling Tower Exhaust Systems
}

\author{
Enderaaj Singh ${ }^{1}$, Sukanta Roy ${ }^{1,}{ }^{*}$, Yam Ke San ${ }^{1}$, Law Ming Chiat $^{1}$ \\ 1 Department of Mechanical Engineering, Faculty of Science and Engineering, Curtin University Malaysia, CDT 250, Miri 98009, Malaysia
}

\section{ARTICLE INFO
ABSTRACT}

\section{Article history:}

Received 27 July 2021

Received in revised form 19 December 2021

Accepted 26 December 2021

Available online 24 January 2022

\begin{abstract}
The technologies surrounding renewable energy have been receiving surmountable attention to producing clean energy and reducing the dependency on depleting fossil fuel sources. In this context, research investigations on vertical axis wind turbines (VAWT) in free stream flow condition has been extensively conducted to improve the energy extraction efficiency from the wind. VAWTs are particularly advantageous in locations not suitable for conventional horizontal axis wind turbines (HAWT). However, the applications of VAWTs are still limited due to their lower performances compared to their counterparts. Furthermore, the wind energy extraction problem is more prominent in urban areas with unpredictable and inadequate wind speed conditions. The present study focuses on an alternative way to harness wind energy from unnatural sources such as cooling tower exhaust systems with the reliable and consistent exhaust air. A three-dimensional numerical study has been conducted to investigate the performance of a 3-bladed H-Darrieus wind turbine (HDWT) using S1046 airfoils of four different solidities under accelerated wind conditions of a cooling tower. The HDWT model is positioned at the cooling tower outlet, where it rotates using sliding mesh to measure the power output. Shear stress transport (SST) k- $\omega$ turbulence model solver was used to solve the implicit unsteady Reynolds-Averaged Navier-Stokes equations. It is observed that the higher solidity HDWT reached peak power coefficient at a lower tip speed ratio (TSR). In contrast, lower solidity HDWT achieved peak power coefficient at higher TSR. The higher solidity 0.375 and 0.450 produced a maximum power coefficient of 0.233 at TSR of 2.0.
\end{abstract}

\section{Keywords:}

Wind Turbines; Exhaust Energy

Extraction; Turbine Solidity;

Computational Fluid Dynamics

\section{Introduction}

Fossil fuels are the primary contributor of energy source as it covers $84 \%$ of the world's energy to fulfil the inevitable increase in energy demand due to population and industrial growth [1]. This non-renewable energy source is heavily relied on as it is cheap, efficient, and convenient. However, the rise in environmental problems due to greenhouse gas emissions from excessive combustion of fossil fuels is a concerning matter. Energy production from fossil fuels has reached an all-time high of 32.3 billion metric tons as of 2012 and is predicted to reach 43.2 billion metric tons by 2040 [2]. The

\footnotetext{
* Corresponding author.

E-mail address: sukanta.roy@curtin.edu.my
}

https://doi.org/10.37934/arfmts.91.2.5161 
fast depletion of conventional energy sources further increases the need to find alternative energy sources to meet future energy demands [3]. Due to its stability and growth rate, wind energy production has proven to be a reliable energy source with a steady increase in the installed capacity for the past five years [4]. However, the growth rate associated with this method of energy production falls short in meeting the ever-growing energy demand.

Large-scale power production from wind energy uses horizontal axis wind turbines (HAWT) at locations with strong natural winds, mainly available at open and remote areas or near sea or hill locations [5]. Urbanisation has caused a rise in energy demand in highly populated areas. Alternative ways are needed to harness wind energy as HAWTs are not suitable for urban locations due to limited land space, turbulent wind conditions and high noise levels. Vertical axis wind turbines (VAWTs) are better suited for micro-electricity generation in urban areas due to smaller and simpler design advantages, low starting speed, low noise level, omnidirectional properties, and adaptability to urban area turbulent wind conditions. In addition, VAWTs are easier to install with a lower maintenance cost $[6,7]$. There are two main classifications of VAWT, a drag-type named Savonius VAWT, and a lifttype named Darrieus VAWT [7]. Various studies are being conducted further to hone the VAWTs' efficiency for urban applications. Several studies successfully proved VAWT's sustainability by integrating its design to the existing urban infrastructure such as tall buildings, roadside dividers, and lamp posts [6,7]. Much attention was given to H-Darrieus wind turbines (HDWT) in numerous studies as it provides better efficiency than Savonius turbines [6,8-14]. Improving HDWT has been actively executed, especially to enhance its start-up properties, as it lacks compared to Savonius type VAWT. The major factor which determines how an HDWT performs is the type of airfoil that is used. Loutun et al., [8] conducted simulation study of various symmetrical and non-symmetrical NACA airfoils which shows NACA 0018 producing highest power coefficient of 0.30 . Moreover, the symmetrical NACA airfoils has higher operating range than non-symmetrical airfoils. Hashem and Mohamed [9] conducted an extensive simulation study on 24 airfoils consisting of symmetrical and nonsymmetrical shapes from eight different series. The S-1046 airfoil was identified as the best performing airfoil, producing the highest maximum power coefficient. Studies on HDWT indicated that the number of blades and chord length are factors of the turbine's solidity, which are essential turbine design parameters [10-12]. Various other studies on HDWT parameters such as pitch angles, aspect ratio, strut effect and different performance enhancement method using flow augmenters were also studied [13-15].

However, in tropical countries, such as Malaysia, have unpredictable and low average wind speed and suffer to harness natural wind power efficiently. Harnessing wind energy from artificial, unnatural sources like the consistent exhaust air from a cooling tower outlet can be a solution to generate efficient power as it expels a high wind speed of up to $16 \mathrm{~m} / \mathrm{s}$ [16]. Chong et al., [17] and Tabatabaeikia et al., [18] conducted experiments and numerical studies to maximise and measure the performance of a 5-bladed lift type VAWT in extracting energy from cooling tower exhaust air. Optimum locations of VAWT with the use of guide vanes, modified plate diffusers and separator plate successfully increased the VAWT rotational speed resulting in 13\% energy recovery and reducing the power consumption by the cooling tower fan motor $[17,18]$. Berhanu et al., [19] experimentally used enclosure and drag force blocker in an exhaust air application and successfully increased the exhaust air speed approaching a Savonius type turbine by four times which can potentially increase its performance by $86.8 \%$. Still, the energy recovery efficiency was not calculated. Nimje and Gandhi [20] extracted energy from a high exhaust air filter duct of a cement manufacturing plant with a 6 bladed turbine, producing $35 \mathrm{~W}$ power.

Existing literature for exhaust air recovery reports poor turbine performances, especially from cooling towers, which is as low as $13 \%[17,18]$. The study of cooling towers lacks a suitable selection 
of turbines as using a different VAWT type with proper parameters can further improve the exhausted wind energy recovery system. Several VAWT parameters are yet to be investigated under accelerated wind condition such as the rotor's solidity. This study aims to optimise the HDWT design under accelerated flow condition of a cooling tower in a three-dimensional numerical analysis. This study is focused on investigating how solidities of an airfoil affects the HDWT performance by calculating the average power coefficient that can be produced.

\section{Methodology}

\subsection{Key Performance Parameter}

Tip speed ratio (TSR), shown in Eq. (1) and solidity $(\sigma)$, shown in Eq. (2) are the key design parameters for this study, where $\omega$ is the HDWT angular velocity [rad/s], $R$ is the radius of HDWT [m], $V_{\infty}$ is the oncoming wind velocity [m/s], $N$ is the number of blades, $c$ is the chord length [m] and $D$ is the diameter of HDWT [m]. Eq. (3) and Eq. (4) shows the average moment coefficient, $C_{m}$ and average power coefficient, $C_{p}$, respectively for the performance measurement of HDWT as function of average mechanical torque, $\mathrm{T}[\mathrm{Nm}]$, density, $\rho\left[\mathrm{kg} / \mathrm{m}^{3}\right]$, HDWT swept area, $\mathrm{A}\left[\mathrm{m}^{2}\right]$, and wind velocity $V_{\infty}[\mathrm{m} / \mathrm{s}][7,9]$

$$
\begin{aligned}
& T S R=\frac{\omega R}{V_{\infty}} \\
& \sigma=\frac{N c}{D} \\
& C_{m}=\frac{T}{0.5 \rho A R V_{\infty}^{2}} \\
& C_{p}=\frac{T \omega}{0.5 \rho A V_{\infty}^{3}}=\frac{T}{0.5 \rho A R V_{\infty}^{2}} \times \frac{R \omega}{V_{\infty}}=C_{m} \times T S R
\end{aligned}
$$

\subsection{H-Darrieus Wind Turbine and Cooling Tower Parameters}

The HDWT used is a 3-bladed with S-1046 blades, adapted from the previous study [21]. Table 1 shows the parameter of HDWT in this study, and Figure 1 shows the scaled-down cooling tower dimensions adapted from a study by Liu et al., [22].

\section{Table 1}

HDWT parameters

\begin{tabular}{ll}
\hline Parameter & Value \\
\hline Airfoil profile & S-1046 \\
Number of blades $(N)$ & 3 \\
Diameter $(D)$ & $456 \mathrm{~mm}$ \\
Span $(H)$ & $200 \mathrm{~mm}$ \\
Chord length $(c)$ & $34.2 \mathrm{~mm}, 45.6 \mathrm{~mm}, 57.0 \mathrm{~mm}$, \\
& $68.4 \mathrm{~mm}$ \\
Solidity ratio $(\sigma)$ & $0.225,0.3,0.375,0.45$ \\
\hline
\end{tabular}




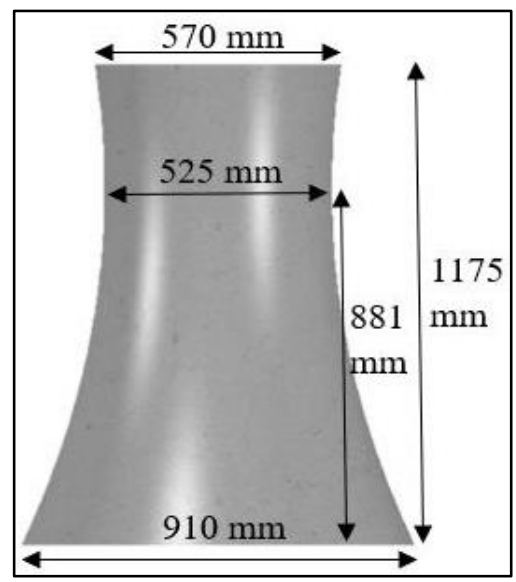

Fig. 1. Cooling tower dimensions

\subsection{Computational Domain with Mesh and Physics Set-Up}

This simulation study computational domain consists of a stationary and a rotating zone region, as shown in Figure 2. Solidworks, a computer-aided designing software, was used to design the domain and HDWT, then imported into Star CCM+, a computational fluid dynamics software to carry out this 3-dimensional numerical study. The stationary domain starts with a cooling tower control volume which then extends into a rectangular control volume. The dimension of the cooling tower domain has been presented in Figure 1. To avoid wall blockage effect and reverse flow, the cuboidal control volume dimension was made big enough by setting it using the ratio of the cooling tower outlet diameter $\left(D_{o}=570 \mathrm{~mm}\right)$ as shown in Figure 2. The HDWT is placed in the rotating region, $0.5 \mathrm{D}$ ( $D=H D W T$ diameter) away from the cooling tower outlet with an interface created and the blades set for no-slip wall boundary. Two velocity inlet is set, including ambient air effect of $2 \mathrm{~m} / \mathrm{s}$ as shown in Figure 2 and $3.7 \mathrm{~m} / \mathrm{s}$ at the cooling tower base to achieve $9 \mathrm{~m} / \mathrm{s}$ at cooling tower outlet accelerated by the converging shape. 3D Polyhedral mesh is used for the whole domain with mesh refinement at the wake region, around HDWT and blades domain. Sliding mesh is set for the stationary and rotating region interface. The three-dimensional implicit unsteady Reynolds-Averaged Navier-Stokes (URANS) equations were solved using shear stress transport (SST) (Menter) $k-\omega$ turbulence model solver with $2^{\text {nd }}$ order temporal discretisation applied. This URANS turbulence model is used to accurately predict turbine performance with its powerful near wall treatment under adverse pressure gradients [23]. The prism layer around blades is created to achieve $\mathrm{y}^{+}$value close to 1 . Constant air density of 1.18415 $\mathrm{kg} / \mathrm{m}^{3}$ and dynamic viscosity of $1.85508 \times 10^{-5} \mathrm{~Pa}$.s was used at the inlet. The turbine's rotational speed was set from $59.211 \mathrm{rad} / \mathrm{s}$ to $157.89 \mathrm{rad} / \mathrm{s}$ to obtain a TSR range of 1.5 to 4.0. Time step size was set to rotate the HDWT by $5^{\circ}$, and 20 inner iteration was used to obtain quasi-static converged solution. 


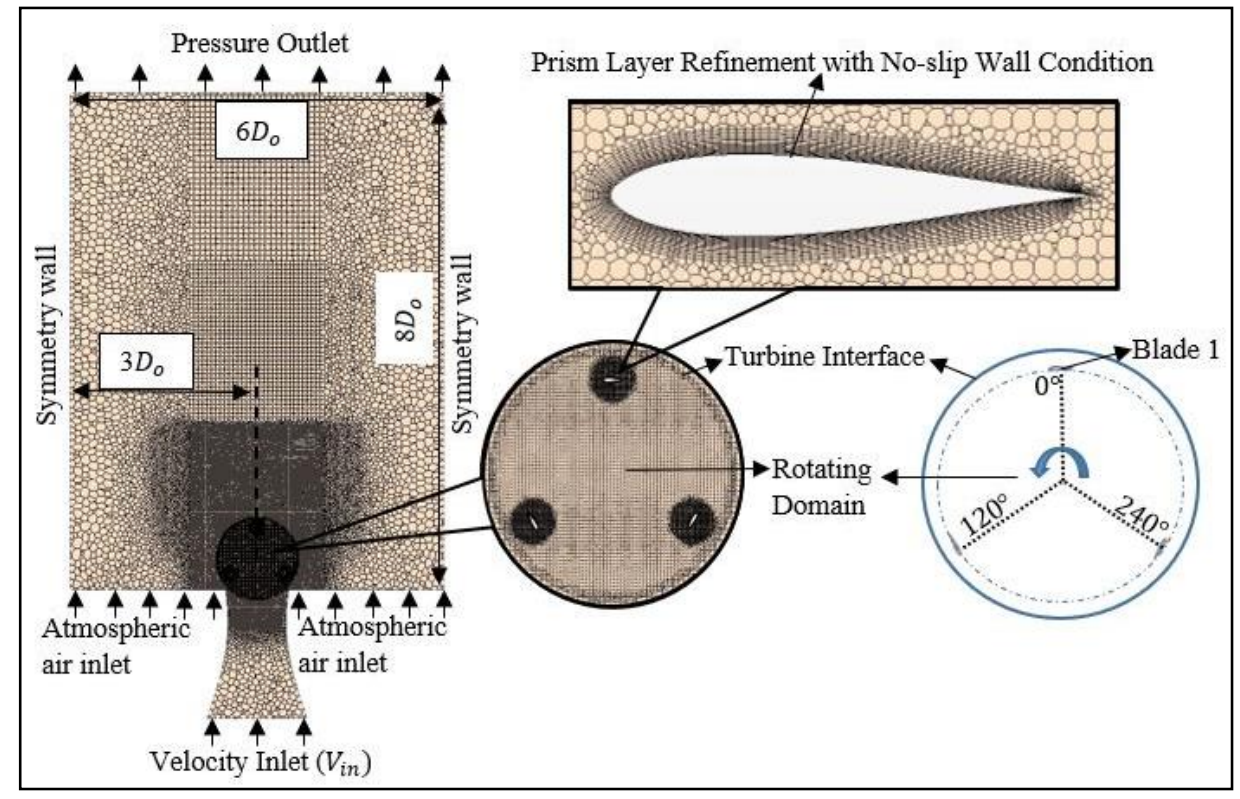

Fig. 2. Meshed computational domain

\subsection{Mathematical Equation}

Shear stress transport (SST) k- $\omega$ turbulence model is used for this study. The incompressible turbulent airflow around the wind turbine is governed by the unsteady Reynolds averaged NavierStokes' (URANS) equations which are the conservation of mass and momentum given by Eq. (5) and Eq. (6) respectively.

$\frac{\partial u_{i}}{\partial t}+\frac{\partial u_{i}}{\partial x_{i}}=0$

$\frac{\partial u_{i}}{\partial t}+u_{i} \frac{\partial u_{i}}{\partial x_{j}}=-\frac{1}{\rho} \frac{\partial p}{\partial x_{i}}-\frac{\partial}{\partial x_{j}}\left[v\left(\frac{\partial u_{i}}{\partial x_{j}}+\frac{\partial u_{j}}{\partial x_{i}}-\frac{2}{3} \delta_{i j} \frac{\partial u_{i}}{\partial x_{i}}\right)\right]+\frac{\partial}{\partial x_{j}}\left(\overline{-\grave{u}_{\imath} \grave{u}_{J}}\right)$

The governing equations of the SST $\mathrm{k}-\omega$ model is turbulence kinetic energy, $k$ and specific turbulence dissipation rate, $\omega$ given as Eq. (7) and Eq. (8) respectively.

$\frac{\partial(\rho k)}{\partial t}+\frac{\partial\left(\rho \overline{u_{j}} k\right)}{\partial x_{j}}=\frac{\partial}{\partial x_{j}}\left(\Gamma_{k} \frac{\partial k}{\partial x_{j}}\right)+G_{k}-Y_{k}+S_{k}$

$\frac{\partial(\rho \omega)}{\partial t}+\frac{\partial\left(\rho \overline{u_{j}} \omega\right)}{\partial x_{j}}=\frac{\partial}{\partial x_{j}}\left(\Gamma_{\omega} \frac{\partial \omega}{\partial x_{j}}\right)+G_{\omega}-Y_{\omega}+S_{\omega}$

Where $\Gamma_{k}$ and $\Gamma_{\omega}$ are the effective diffusivities of $k$ and $\omega, G_{k}$ and $G_{\omega}$ show the generation of $k$ and $\omega$ due to mean velocity gradients, $Y_{k}$ and $Y_{\omega}$ signify the dissipation of $k$ and $\omega$ due to turbulence, and $S_{k}$ and $S_{\omega}$ represent source terms for $k$ and $\omega$.

\section{Model Validation}

\subsection{Grid Independence and Time Step Validation}

To ensure the accuracy of the results, grid independence test study was conducted to choose the best mesh size and time step. First, refinement of the computational domain mesh, especially finer 
mesh around HDWT were done to achieve stable $C_{m}$ value once it converges after 7 rotations. 5.6 million cell size shows $C_{m}$ value is acceptable to be use for this study as further refinement of mesh gives $C_{m}$ difference of less than $1 \%$ as shown in Figure 3 . Secondly, the time step size test was conducted by setting four values of time steps to rotate the HDWT by $2.5^{\circ}, 5^{\circ}, 10^{\circ}$ and $15^{\circ}$ degrees. The instantaneous $C_{m}$ value produced by a single blade over 1 converged rotation (360 ) was compared as shown in Figure 4 . The bigger time step overpredicts the $C_{m}$ produced by the blade at the HDWT leeward direction and shifts the peak blade $C_{m}$ to the right towards higher azimuthal angle. This clearly shows smaller time step gives more accurate result. However, to balance with the computational cost, final time step chosen was $5^{\circ}$ as it reaches quasi-static convergence after 60 hours of computational time. In contrast, the $2.5^{\circ}$ time step converges after 300 hours, which is an expensive computational time.



Fig. 3. Grid independence test



Fig. 4. Time step size test

\subsection{Validation Against Past Study}

For further validation, the grid size and time step from section 3.1 was validated against one experimental study of Castelli et al., [24] and one numerical study of Hashem and Mohammed [9]. A normal full rectangular free stream flow domain, without cooling tower was used for this validation using 3-bladed HDWT with parameters as shown in Table 2. Results as shown in Figure 5 confirms the current mesh and time step condition is suitable to be used for the present numerical study as it shows good comparison to the available literature.

Table 2

Validation parameters

\begin{tabular}{ll}
\hline Physics setup & Values \\
\hline Airfoil profile & NACA 0021 \\
Inlet wind speed $\left(V_{\text {in }}\right)$ & $9.00 \mathrm{~m} / \mathrm{s}$ \\
HDWT diameter $(D)$ & $0.515 \mathrm{~m}$ \\
HDWT span $(H)$ & $0.200 \mathrm{~m}$ \\
Solidity ratio $(\sigma)$ & 0.25 \\
Tip speed ratio $($ TSR) & $1.44-3.30$ \\
\hline
\end{tabular}




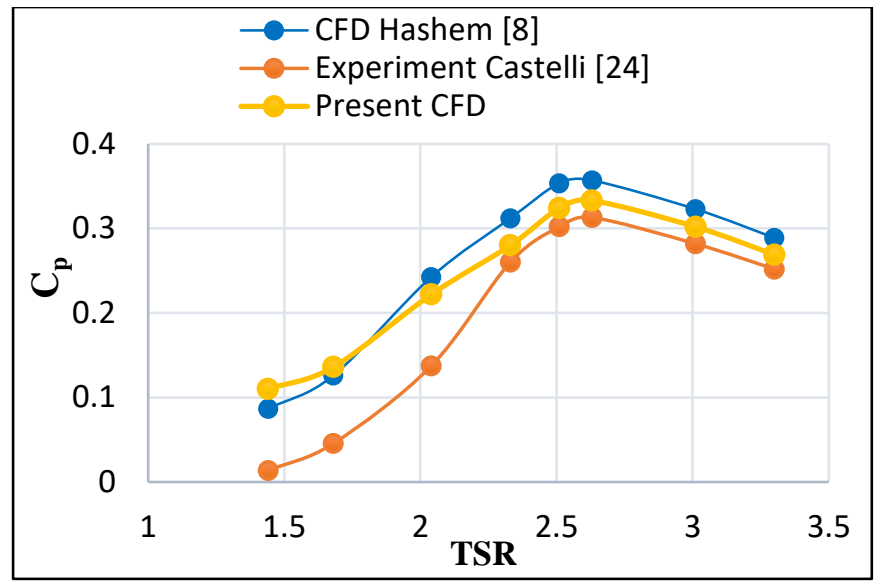

Fig. 5. Computational domain validation

\section{Results and Discussions}

\subsection{Average Moment and Power Coefficients}

Different solidities were studied, producing coefficient of moment and coefficient of power to varying TSRs, as shown in Figure 6 and Figure 7. From the results obtained, it can be observed that the maximum $C_{m}$ and $C_{p}$ at lower TSR is achieved by higher solidity HDWT while at higher TSR, low solidity HDWT performs better. Decreasing the solidity causes maximum $C_{p}$ attained by HDWT shifts towards higher TSR as seen in Figure 7. HDWT with $\sigma=0.375$ and $\sigma=0.45$ produces highest power coefficient of $C_{p}=0.233$ at TSR 2.0. The instantaneous $C_{m}$ contribution of a single blade for a complete $360^{\circ}$ rotation of all HDWT solidity at TSR 2.0 is shown in Figure 8 . The highest moment generated by single HDWT blade of $\sigma=0.225$ is at $\theta=175^{\circ}$, and the peak moment shifts to the right as solidity increases with HDWT of $\sigma=0.45$, giving peak blade moment at $\theta=200^{\circ}$. HDWT blades with $\sigma=0.45$ produce a high positive moment at a wider azimuthal angle from $140^{\circ}$ to $255^{\circ}$ while low $\sigma=0.225$ produces lower positive moment from $135^{\circ}$ to $230^{\circ}$. Overall, the HDWT with blades of solidity 0.375 and 0.45 has the highest moment compared to lower solidity blades at a TSR of 2.0.

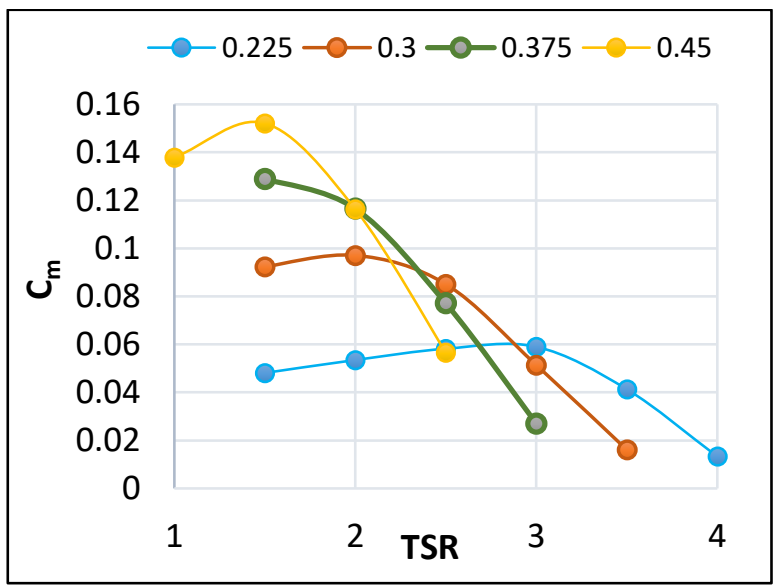

Fig. 6. Moment coefficient of HDWT with solidity $0.225,0.3,0.375$ and 0.45



Fig. 7. Power coefficient of HDWT with solidity $0.225,0.3,0.375$ and 0.45 


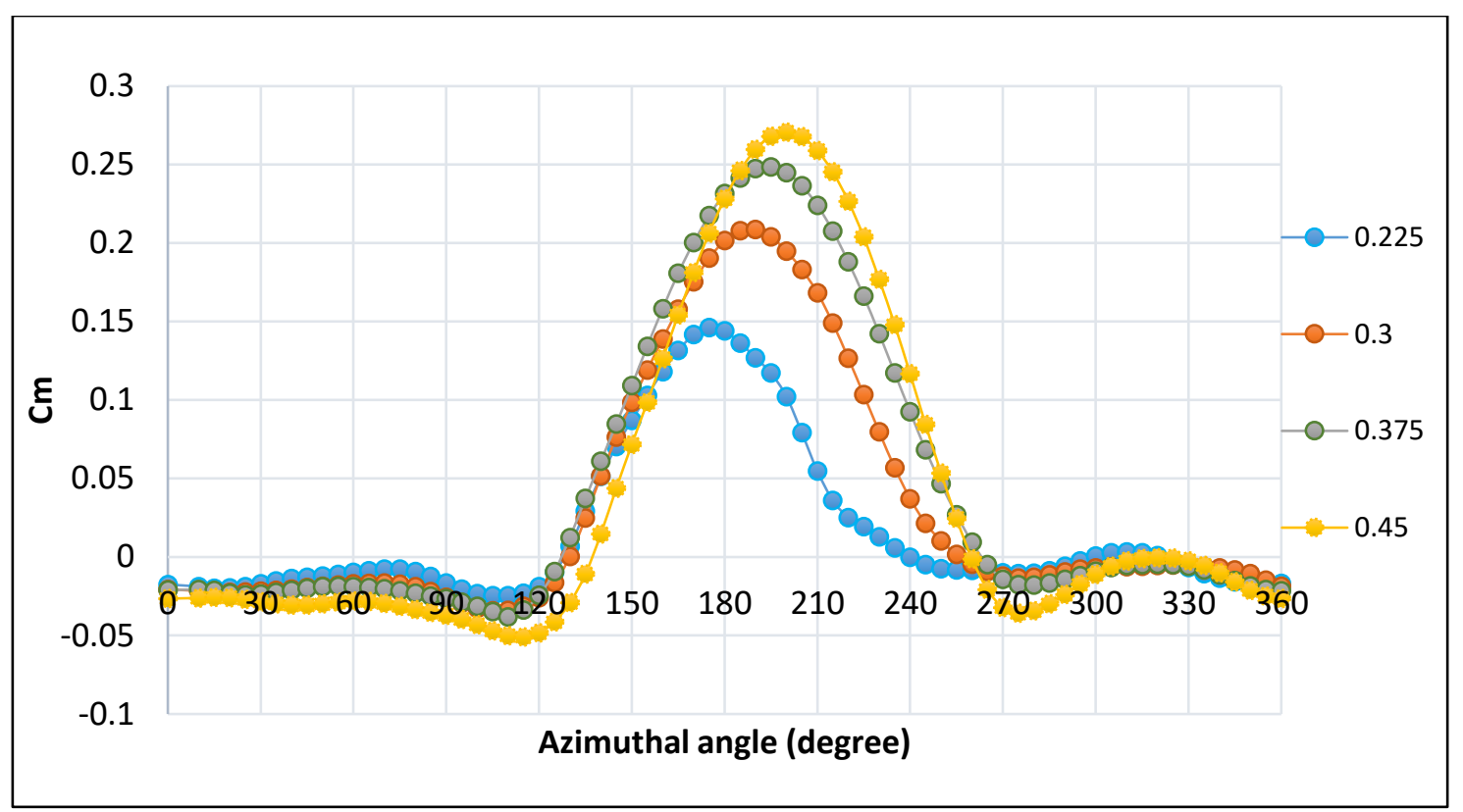

Fig. 8. Single blade instantaneous coefficient of moment against HDWT azimuthal rotation for different solidities at TSR 2.0

\subsection{HDWT Performance Assessment at Different Azimuthal Positions}

Figure 9 and Figure 10 show the instantaneous $C_{m}$ radar plot of all solidities for one complete HDWT rotation at TSR 1.5 and TSR 3.0. At TSR 1.5, the HDWT with the solidity of 0.45 gives the highest moment at all azimuthal angles compared to other solidities with maximum values at $\theta=70^{\circ}, 190^{\circ}$ and $310^{\circ}$ while the lower solidity HDWT achieve peak moment at earlier azimuthal position with $\sigma=0.225$ giving $\max C_{m}$ at $\theta=45^{\circ}, 165^{\circ}$ and $285^{\circ}$. The lower solidity HDWT gives lower $C_{m}$ with some negative moment at certain azimuthal rotation at TSR 1.5. The HDWT experiences the lowest $C_{m}$ values at $\theta=5^{\circ}, 105^{\circ}-125^{\circ}, 225^{\circ}-245^{\circ}$ and $345^{\circ}-360^{\circ}$ at TSR 1.5 . Figure 10 shows that the lowest solidity HDWT performs better at a higher TSR of 3.0. However, the magnitude and difference in $C_{m}$ performance between the high solidity and low solidity HDWT is much greater at TSR 1.5, indicating that the higher solidity HDWT gives overall better performance in terms of power production. For all solidities at TSR 3.0, the HDWT produces peak $C_{m}$ at the same azimuthal position of $\theta=75^{\circ}, 195^{\circ}$ and $315^{\circ}$. 


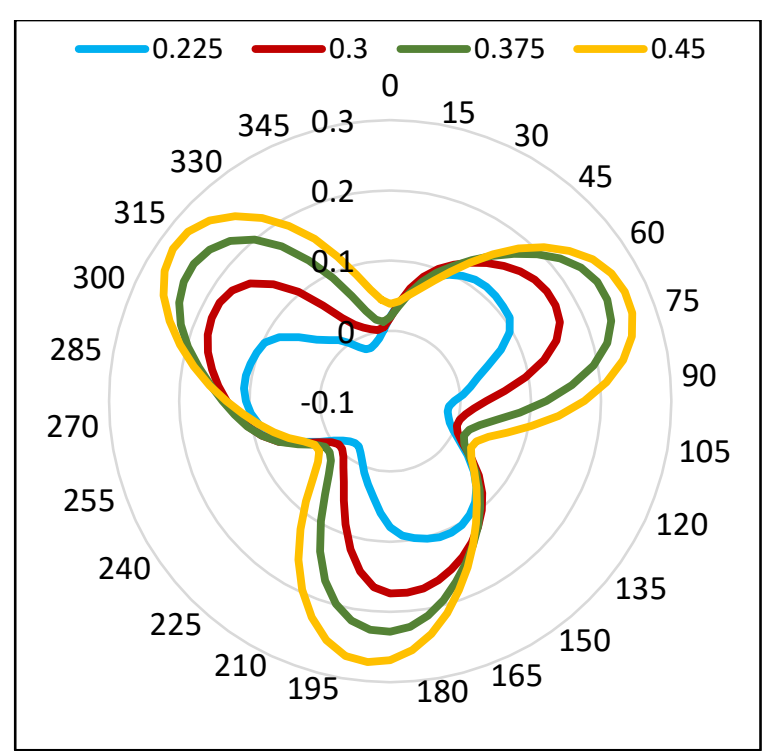

Fig. 9. Instantaneous coefficient of moment against HDWT azimuth angles for solidities $0.225,0.3,0.375$ and 0.45 at TSR 1.5

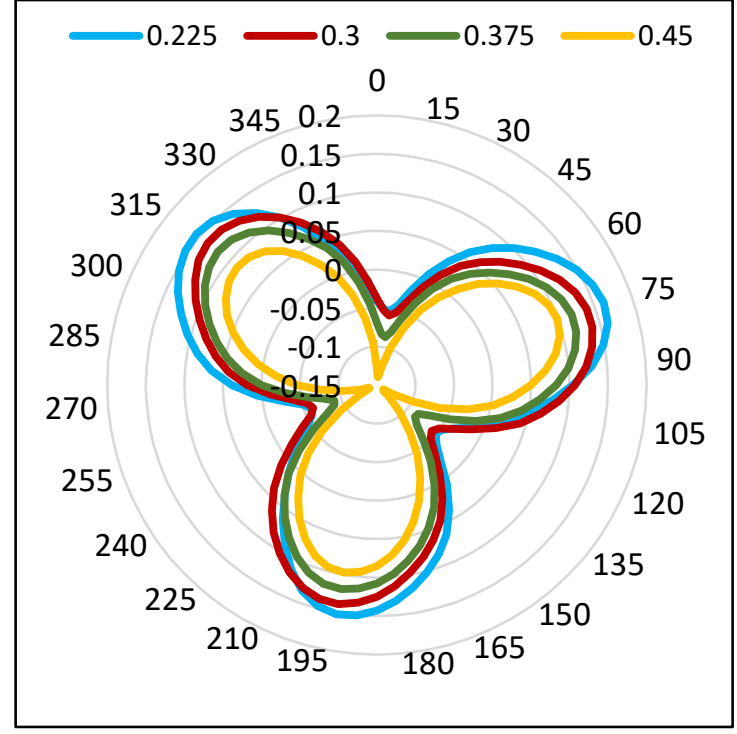

Fig. 10. Instantaneous coefficient of moment against HDWT azimuth angles for solidities $0.225,0.3,0.375$ and 0.45 at TSR 3.0

\section{Conclusion}

A three-dimensional computational simulation study was conducted for an H-Darrieus VAWT with S-1046 airfoils to investigate the performance of 4 different solidities at TSR 1.5 to 4.0. Results obtained show higher solidity HDWT produces higher average power at low TSR while lower solidity HDWT performs better at higher TSR for the cooling tower exhaust application. The lower solidity HDWT, $\sigma=0.225$ has a wider range of operation; however, the maximum power coefficient of 0.233 was achieved by higher solidity HDWT, $\sigma=0.375$ and $\sigma=0.45$ at TSR 2.0. Further, the peak performance is obtained at azimuthal positions of $\theta=75^{\circ}, 195^{\circ}$ and $315^{\circ}$. As a future scope, investigations on the application of guide vanes and diffusers for performance enhancement will be conducted to optimise the system.

\section{Acknowledgement}

The authors would like to thank the Ministry of Higher Education (MOHE) Malaysia for the financial support by awarding the Fundamental Research Grant Scheme (FRGS Grant: FRGS/1/2018/TK10/CURTIN/03/1) to carry out this project.

\section{References}

[1] Ritchie, Hannah, and Max Roser. "Renewable Energy." Our World in Data. Accessed May 16, 2021. https://ourworldindata.org/renewable-energy.

[2] Kibria, Ahsan, Sherzod B. Akhundjanov, and Reza Oladi. "Fossil fuel share in the energy mix and economic growth." International Review of Economics \& Finance 59 (2019): 253-264. https://doi.org/10.1016/i.iref.2018.09.002

[3] Ritchie, Hannah, and Max Roser. "Fossil Fuels." Our World in Data. Accessed May 16, 2021. https://ourworldindata.org/fossil-fuels.

[4] REN21 Secretariat. "Renewables 2020 Global Status Report." REN21, Paris, 2020. https://www.ren21.net/wpcontent/uploads/2019/05/gsr 2020 full report en.pdf.

[5] Nobile, Rosario, Maria Vahdati, Janet F. Barlow, and Anthony Mewburn-Crook. "Unsteady flow simulation of a vertical axis augmented wind turbine: A two-dimensional study." Journal of Wind Engineering and Industrial Aerodynamics 125 (2014): 168-179. https://doi.org/10.1016/i.jweia.2013.12.005 
[6] Kumar, Rakesh, Kaamran Raahemifar, and Alan S. Fung. "A critical review of vertical axis wind turbines for urban applications." Renewable and Sustainable Energy Reviews $89 \quad$ (2018): $281-291$. https://doi.org/10.1016/j.rser.2018.03.033

[7] Roy, Sukanta, and Antoine Ducoin. "Unsteady analysis on the instantaneous forces and moment arms acting on a novel Savonius-style wind turbine." Energy Conversion and Management 121 (2016): 281-296. https://doi.org/10.1016/i.enconman.2016.05.044

[8] Loutun, Mark Jason Thomas, Djamal Hissein Didane, Mohd Faizal Mohideen Batcha, Kamil Abdullah, Mas Fawzi Mohd Ali, Akmal Nizam Mohammed, and Lukmon Owolabi Afolabi. "2D CFD Simulation Study on the Performance of Various NACA Airfoils." CFD Letters 13, no. 4 (2021): 38-50. https://doi.org/10.37934/cfdl.13.4.3850

[9] Hashem, I., and M. H. Mohamed. "Aerodynamic performance enhancements of H-rotor Darrieus wind turbine." Energy 142 (2018): 531-545. https://doi.org/10.1016/i.energy.2017.10.036

[10] Rezaeiha, Abdolrahim, Hamid Montazeri, and Bert Blocken. "Towards optimal aerodynamic design of vertical axis wind turbines: Impact of solidity and number of blades." Energy 165 (2018): 1129-1148. https://doi.org/10.1016/i.energy.2018.09.192

[11] Subramanian, Abhishek, S. Arun Yogesh, Hrishikesh Sivanandan, Abhijit Giri, Madhavan Vasudevan, Vivek Mugundhan, and Ratna Kishore Velamati. "Effect of airfoil and solidity on performance of small scale vertical axis wind turbine using three dimensional CFD model." Energy 133 (2017): 179-190. https://doi.org/10.1016/j.energy.2017.05.118

[12] Qamar, Sayyad Basim, and Isam Janajreh. "A comprehensive analysis of solidity for cambered darrieus VAWTs." International Journal of Hydrogen Energy 42, no. $30 \quad$ (2017): 19420-19431. https://doi.org/10.1016/i.ijhydene.2017.06.041

[13] Bhutta, Muhammad Mahmood Aslam, Nasir Hayat, Ahmed Uzair Farooq, Zain Ali, Sh Rehan Jamil, and Zahid Hussain. "Vertical axis wind turbine-A review of various configurations and design techniques." Renewable and Sustainable Energy Reviews 16, no. 4 (2012): 1926-1939. https://doi.org/10.1016/i.rser.2011.12.004

[14] Hand, Brian, Ger Kelly, and Andrew Cashman. "Aerodynamic design and performance parameters of a lift-type vertical axis wind turbine: A comprehensive review." Renewable and Sustainable Energy Reviews 139 (2021): 110699. https://doi.org/10.1016/i.rser.2020.110699

[15] Wong, Kok Hoe, Wen Tong Chong, Nazatul Liana Sukiman, Sin Chew Poh, Yui-Chuin Shiah, and Chin-Tsan Wang. "Performance enhancements on vertical axis wind turbines using flow augmentation systems: A review." Renewable and Sustainable Energy Reviews 73 (2017): 904-921. https://doi.org/10.1016/i.rser.2017.01.160

[16] Hensley, John C. "Cooling Tower Fundamentals. Compiled from the knowledge and experience of the entire SPX Cooling Technologies staff. SPX Cooling Technologies." Inc. Overland Park, Kansas, USA (2009).

[17] Chong, W. T., W. P. Hew, S. Y. Yip, A. Fazlizan, S. C. Poh, C. J. Tan, and H. C. Ong. "The experimental study on the wind turbine's guide-vanes and diffuser of an exhaust air energy recovery system integrated with the cooling tower." Energy Conversion and Management $87 \quad$ (2014): $145-155$. https://doi.org/10.1016/j.enconman.2014.07.009

[18] Tabatabaeikia, Seyedsaeed, Nik Nazri Bin Nik Ghazali, Wen Tong Chong, Behzad Shahizare, Nima Izadyar, Alireza Esmaeilzadeh, and Ahmad Fazlizan. "Computational and experimental optimization of the exhaust air energy recovery wind turbine generator." Energy Conversion and Management 126 (2016): 862-874. https://doi.org/10.1016/i.enconman.2016.08.039

[19] Berhanu, Hailemariam, Dawit Gudeta, A. Haiter Lenin, and B. Karthikeyan. "Numerical and experimental investigation of an exhaust air energy recovery Savonius wind turbine for power production." Materials Today: Proceedings (2021). https://doi.org/10.1016/i.matpr.2021.02.675

[20] Nimje, Akhilesh A., and Neel Mukeshbhai Gandhi. "Design and development of small wind turbine for power generation through high velocity exhaust air." Renewable Energy 145 (2020): 1487-1493. https://doi.org/10.1016/i.renene.2019.06.065

[21] Singh, Enderaaj, Sukanta Roy, and Yam Ke San. "Numerical Analysis of Exhaust Air Energy Extractor for Cooling Tower Applications." In IOP Conference Series: Materials Science and Engineering, vol. 943, no. 1, p. 012035. IOP Publishing, 2020. https://doi.org/10.1088/1757-899X/943/1/012035

[22] Liu, Zhenqing, Chong Zhang, and Takeshi Ishihara. "Numerical study of the wind loads on a cooling tower by a stationary tornado-like vortex through LES." Journal of Fluids and Structures 81 (2018): 656-672. https://doi.org/10.1016/i.jfluidstructs.2018.06.001

[23] Yusuf, Siti Nurul Akmal, Yutaka Asako, Nor Azwadi Che Sidik, Saiful Bahri Mohamed, and Wan Mohd Arif Aziz Japar. "A Short Review on RANS Turbulence Models." CFD Letters 12, no. 11 (2020): 83-96. https://doi.org/10.37934/cfdl.12.11.8396 
[24] Castelli, Marco Raciti, Alessandro Englaro, and Ernesto Benini. "The Darrieus wind turbine: Proposal for a new performance prediction model based on CFD." Energy 36, no. 8 (2011): 4919-4934. https://doi.org/10.1016/j.energy.2011.05.036 